\title{
A COMPARISON OF HALOTHANE AND NEUROLEPTANAESTHESIA FOR DISC SURGERY: HAEMODYNAMIC AND METABOLIC STUDIES*
}

\author{
MiCHAEL KeÉRI-SZÁNTó, M.D., F.A.C.C.P.†
}

EvEN UNDER OPTIMAL CONDITIONS general anaesthesia is a significant stress. The extent of this stress will be obvious to anyone who cares to compare a well-maintained patient recovering from six hours' anaesthesia with the same patient awakened after six hours' natural sleep. The nature of the stress is much harder to define. A useful working hypothesis assumes that it has to do with circulatory changes and there is lively controversy whether these are secondary to altered metabolic requirements ${ }^{1,2}$ or whether on the contrary the metabolism adapts as the result of circulatory disturbances. ${ }^{2,3}$

It must be remembered that major surgery, with its blood loss, fluid shifts and catecholamine release, might of itself produce haemodynamic changes that would mask or potentiate effects of the anaesthetic upon the circulation. Animal experiments and data from non-operated volunteers therefore can serve only as guideposts in the quest for precise definition of the events during surgery. Such knowledge may be used as a rational basis for choosing or rejecting a particular anaesthetic under a certain set of circumstances.

This report deals with observations made on 44 unselected patients subjected to lumbar dise surgery.

\section{Techniques}

\section{Surgery}

Following induction on the stretcher, patients were turned and installed in a knee-chest position, with their shoulders supported on bolsters and the abdomen moving freely. Surgery consisted essentially of the exploration of one or two intervertebral spaces, usually on one side, occasionally on both. In twelve patients it was deemed necessary to pack the intervetebral space with autogenous bonegraft removed from the iliac crest during the same operation. All these patients received blood transfusions during surgery, while in the simple disc operations 5 per cent glucose and lactated Ringer's solution were used for volume replacement.

\section{Anaesthesia}

Patients received routine premedication. Anaesthesia times were from 100 to 350 minutes. Features common to all anaesthetics were induction with thiopental

"From the Departments of Anaesthesia and Neurosurgery, Notre-Dame Hospital, Montreal. Presented in part to a panel on anaesthesia in neurosurgery during the Fourth World Congress of Anaesthesiologists, London, September 1968.

$\uparrow$ Associate Professor of Anaesthesia, University of Western Ontario, and Chief of Service, Department of Anaesthesia, Victoria Hospital, London, Ontario. 
$1 \mathrm{mg} / \mathrm{lb}$ body weight, endotracheal intubation with the aid of succinylcholine, mechanical ventilation with 67 per cent nitrous oxide, and the use of d-tubocurare as needed (usually around $15 \mathrm{mg}$ ). Ventilation was of the order of 10 to 12 $\mathrm{L} / \mathrm{min}$, the inflow of fresh gases was $4.5 \mathrm{~L} / \mathrm{min}$, and partial rebreathing was utilized by which arterial $\mathrm{PCO}_{2}$ was maintained between 35 and $40 \mathrm{~mm} \mathrm{Hg}$.

To this basic anaesthesia was added in the halothane series ( 21 patients) 1.5 per cent of halothane vapour up to the moment of intubation, 1 per cent from then to skin incision, and maintenance doses ( 0.5 to 0.75 per cent) thereafter until the final twenty minutes of surgery when the vapour was turned off altogether. In the NLA series ( 23 patients) $5 \mathrm{ml}$ Innovar was added to the induction and 1-2 $\mathrm{ml}$ increments were used thereafter as required.

All patients responded to their names in the operating room. Those who tolerated their endotracheal tubes were attached to a respirator in the recovery room and had their respirations assisted as long as they were comfortable in this fashion. This could be achieved in 4 halothane and in $13 \mathrm{NLA}$ patients.

Patients were prepared for this study by the insertion of an 18-gauge plastic cannula in the radial artery and a 15-gauge plastic tube into the superior vena cava (svc) by percutaneous puncture of the subclavian vein. With practice, the entirc preparation (cannulation, setting up of equipment, preparation of dye solution) added less than 30 minutes to the usual anaesthetic time, even though the anaesthetist performed all these tasks in addition to his regular duties. The patient was assigned by lot to one of the two treatment groups only after base-line values were recorded, but not calculated. The recorded parameters consisted of repeated cardio-green ${ }^{\circledR}$ dye dilution curves and, in 17 patients, blood gas studies and the calculation of expired $\mathrm{CO}_{2}$ volumes midway through surgery. In order to validate the use of svc blood for the calculation of arterial-venous oxygen gradients we have compiled and analysed oxymetry data from 200 consecutive conscious patients studied at the hospital's cardiac catheterisation laboratory.

\section{RESULtS}

Figure 1 presents average cardiac outputs in the two treatment groups during the course of induction, surgery, and the postanaesthetic period, expressed as percentages of the base-line value. Figure 2 shows the relationship between pulmonary artery and svc oxygen saturation in unanaesthetized patients. Figure 3 contains data obtained midway through surgery, corresponding to point $\mathrm{C}$ in Figure 1. It shows $\mathrm{CO}_{2}$ production measured in the exhaled gases. Oxygen uptake has been calculated from the cardiac output and the oxygen gradient between the radial artery and the superior vena cava. Both sets of data are expressed as percentages of predicted values in the literature. ${ }^{4}$

\section{Discussion}

This investigation is unique as far as we could ascertain in that (a) it measures cardiac output in clinical material under particularly difficult conditions (the patients were turned twice and were twice transported for a total distance of about $\mathbf{1 5 0}$ feet during each run); $(b)$ in almost half of the studies cardiac 
output determinations were combined with $\mathrm{CO}_{2}$ output and svc oxygen uptake calculations. One or the other of the latter is essential if one wishes to go beyond a simple statement about cardiac output and wants to form a value judgment about the adequacy or inadequacy of circulation. In the present instance the two combined allow deeper insight into the different action of two anaesthetic agents upon the circulation and point the way to further clinically significant studies.

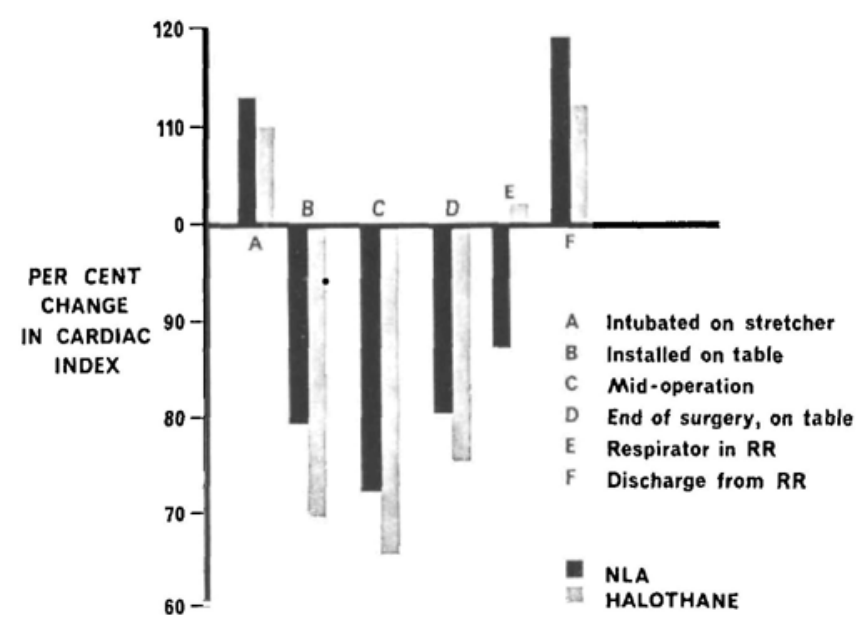

Frgure 1. Average changes in cardiac output from preinduction values through anaesthesia, surgery, and recovery. The initial cardiac index was $3.85 \pm 0.15 \mathrm{~L} / \mathrm{m}^{2} / \mathrm{min}$. The differences between the two treatment groups are not statistically significant at any point. There were 21 halothane and 23 NLA patients in this study.

The cardiac output changes are shown as percentages of the preinduction value and as they stand they are in conflict with earlier data from the literature ${ }^{5}$ where no significant deviation from the preinduction values was found when patients were installed in a comparable position. The results are flawed to the extent that the average preinduction cardiac index $\left(3.8 \pm 0.15 \mathrm{~L} / \mathrm{m}^{2} / \mathrm{min}\right)$ is substantially higher than the accepted norm, presumably due to the discomfort and excitement associated with the placement of cannulae. It could be argued that the subsequent drop represents a return to true resting values rather than anything else. This is borme out by the independent observation, shown in Figure 3, that the $\mathrm{CO}_{2}$ output of these same patients is virtually normal midway through surgery when corrected for age, sex, and size. Note should be made of the cardiac output values at the time of discharge from the recovery room. These averaged $4.3 \pm 0.25$ $\mathrm{L} / \mathrm{m}^{2} / \mathrm{min}$, at a time when most of the temperature changes had been compensated and the patients appeared sedated and free of pain. This amount of circulatory activity was certainly well tolerated by all subjects in this study but it is equally certain that a significant number of patients pass through our recovery rooms for whom it is impossible, or only barely possible, to maintain this level of cardiac activity for any length of time. The need for life-function support (sedation and prolonged respirator treatment) in this latter group ${ }^{6}$ is emphasized and partially explained by the present findings. 


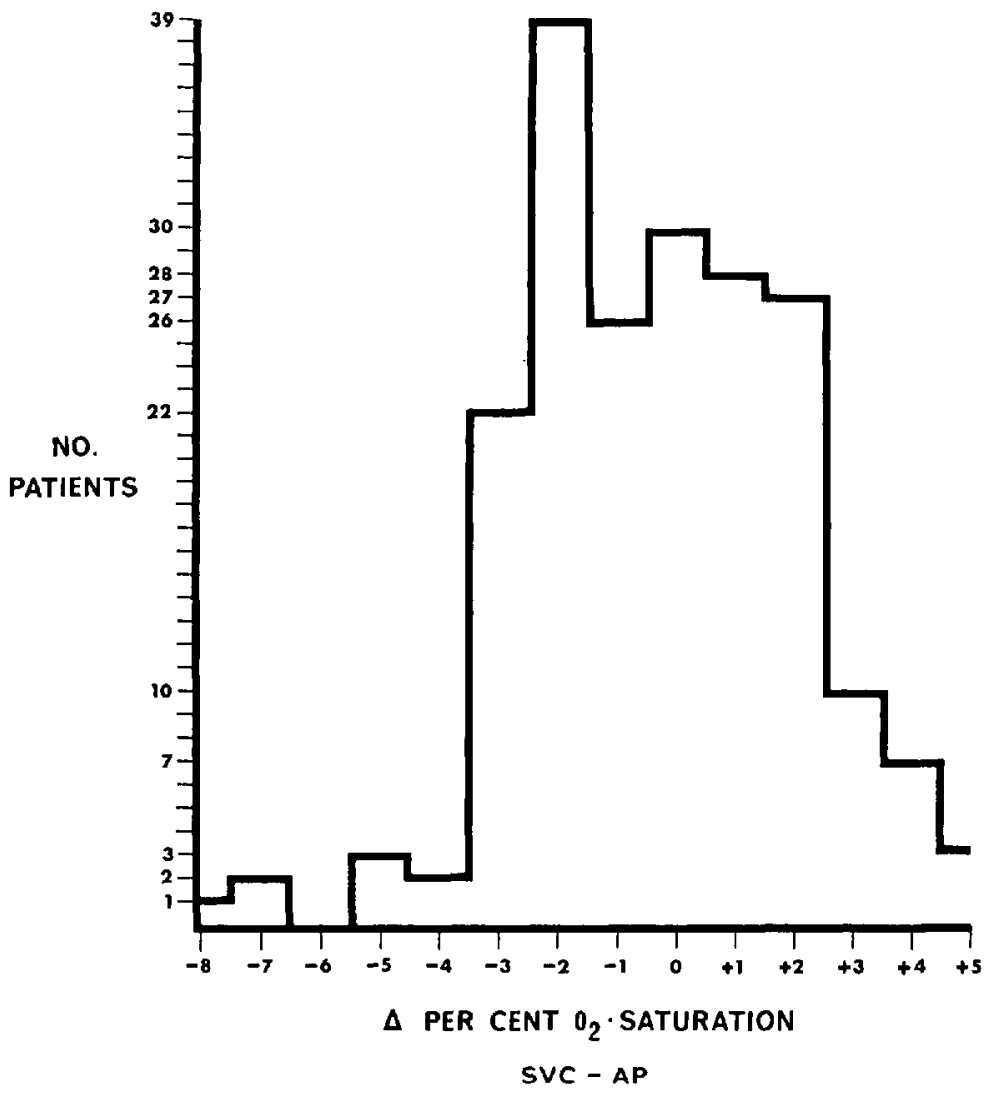

Figure 2. Histogram showing the distribution of superior vena cavapulmonary artery saturation gradients. The data were obtained from two hundred consecutive conscious patients undergoing cardiac catheterization. They inclucle 36 subjects whose arterial oxygen saturation was less than 90 per cent. The mean SCV-AP gradient is -0.5 per cent saturation.

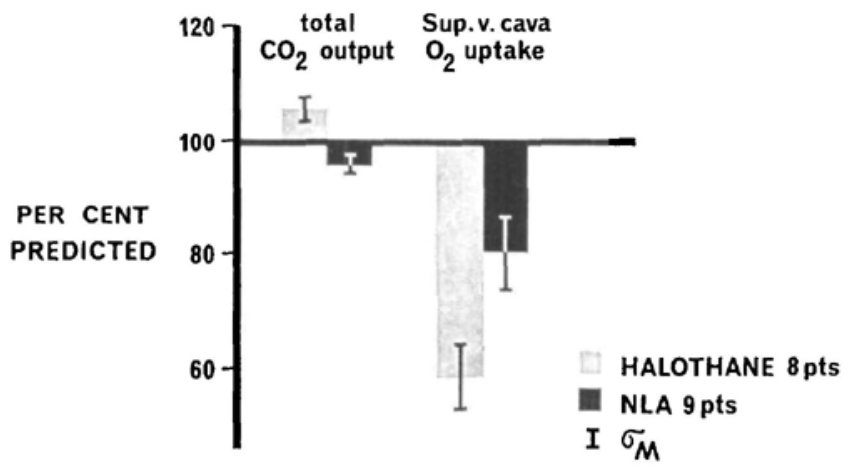

Frgure 3. The data in this figure were obtained at the moment corresponding to point $\mathrm{C}$ in Figure 1, and compared with data obtained by Nunn and Matthews in $1959.4 \mathrm{CO}_{2}$ output was measured at the mouth and has been corrected for age, sex, and the patient's size. Mean $\mathrm{O}_{2}$ uptake, similarly corrected, has been computed from cardiac output and from the oxygen gradient between the radial artery and the superior vena cava. The differences between treatment groups are statistically significant $(p<0.01)$. 
M. KEÉRI-SZÁNTÓ: HALOTHANE VS. NEUROLEPTANAESTHESIA FOR DISC SURGERY 239

Comparison of the oxymetric data from the svc and the pulmonary artery of unanaesthetised subjects (Fig. 2) shows, as expected, that there is very little difference between the two readings even when arterial oxygen saturation is abnormally low, as was the case in many of these subjects. It came all the more as a surprise then that during anaesthesia this relationship seemed to break down completely (Fig. 3). Total oxygen consumption, calculated from the arterial-svc oxygen gradient, resulted in unreasonably low values. These data also differentiated with appreciable sensitivity $(p=0.05)$ between the two treatment groups. The relationship between cardiac output, $\mathrm{CO}_{2}$ production and $\mathrm{O}_{2}$ uptake does not differ significantly from the norms during NLA anaesthesia, although all values are lower than the base line. Statistically significant differences were found in the halothane group between $\mathrm{CO}_{2}$ output (slightly but significantly elevated, $p=$ 0.01 ), cardiac index ( 20 per cent below normal, statistically not significant), and svc oxygen uptake ( 57 per cent of normal, $p=0.001$ ). The explanation for the lower oxygen extraction from the svc bed appears fairly obvious. Cerebral oxygen consumption has been reduced, to a slight extent with NLA and to a much greater degree with halothane. ${ }^{7,8}$ Judged by the behaviour of the cardiac output and the absence of all other signs of hypoxia, it seems unnecessary to invoke the posthypoxic luxury brain perfusion syndrome in these patients. ${ }^{9}$

One must also keep in mind that, while cerebral oxygen consumption was reduced, the total $\mathrm{CO}_{2}$ output remained very close to normal resting values in both treatment groups. This indicates that other organs are producing more than their usual share of $\mathrm{CO}_{2}$. The source of this excess production could be the kidneys, but it is far more likely to be the splanchnic bed.10

The interpretation of these data for everyday clinical practice is not easy. It seems clear that whenever cerebral oxygen extraction becomes the limiting factor in a patient's welfare, halothane should be considered as the agent of choice, in spite of its known action on increasing CSF pressure. ${ }^{11}$ It must be taken into account, however, that the sparing action on brain oxygen requirements occurs at the expense of increased requirements elsewhere, notably in the splanchnic bed. Warnings about the use of halothane in abdominal and particularly in hepatic surgery have been hotly discussed before and were mostly set aside on the basis of extensive retrospective studies showing no increase in morbidity or mortality associated with this agent. ${ }^{12}$ We have previously reported that BSP extraction studies differentiated as long as five days after abdominal surgery between patients exposed to 2 per cent halothane for short periods and those to whom only 1 per cent was exhibited. ${ }^{13}$ The present technique promises to be a valid approach to this important problem, and we hope to report results on abdominal surgery patients in the near future.

\section{SUMMARY}

Cardiac output determinations were carried out on 44 unselected patients before, during, and after spinal surgery. Substantial changes were recorded in the course of each operation but there were no significant differences between two treatment groups receiving either halothane or neuroleptanaesthesia (Innovar ${ }^{(8)}$. 
In 17 of the same patients $\mathrm{CO}_{2}$ output and $\mathrm{O}_{2}$ uptake studies were also carried out. These indicate that while $\mathrm{CO}_{2}$ output remains close to the resting normal, $\mathrm{O}_{2}$ uptake from the superior vena cava bed is significantly more reduced with halothane than with NLA. It follows that in other areas of the organism the reverse must hold true.

On discharge from the recovery room, the mean cardiac index was $4.3 \pm 0.25$ $\mathrm{L} / \mathrm{m}^{2} / \mathrm{min}$. This value underlines the need for cardiac reserve or for the support of vital functions in the immediate postanaesthetic period.

\section{RÉsumé}

On a étudié le débit cardiaque chez 44 malades pris au hazard avant, pendant et après la chirurgie rachidienne. Au cours de chaque opération, on a noté des variations substantielles, mais il n'y a pas eu de différence importante entre les deux groupes observés : ceux qui ont reçu du fluothane ou une neuroleptanesthésie (Innovar).

On a aussi fait des études sur l'élimination de $\mathrm{CO}_{2}$ et l'absorption $\mathrm{d}^{\prime} \mathrm{O}_{2}$ chez 17 de ces malades. Ces études indiquent que, alors que l'élimination de $\mathrm{CO}_{2}$ demeure près de la normale d'un sujet au repos, l'absorption d' $\mathrm{O}_{2}$ du lit de la veine cave supérieure est sensiblement plus diminuée avec l'halothane qu'avec la neuroleptanesthésie. Il s'ensuit qu'ailleurs dans l'organisme le contraire doit être vrai.

Au départ de la salle de réveil, l'index cardiaque moyen était de $4.3 \pm 0.25$ $\mathrm{L} / \mathrm{m}^{2} / \mathrm{min}$. Ceci souligne le besoin de réserve cardiaque ou de support des fonctions vitales durant la période postanesthésique immédiate.

\section{REFERENCES}

1. GatTiker, R. I., et al. Halothane and Hepatic Venous Oxygen Saturation. Anesthesiology. 26: 246 (1965).

2. Price, H. L. et al. Can General Anesthetic Produce Splanchnic Visceral Hypoxya by Reducing Regional Blood Flow? Anesthesiology. 27: 24 (1966).

3. Tamotsu, S.; Mazuzan, J. E.; \& Abajian, J. Halothane and the Heart. Brit. J. Anaesth. 40: 73 (1968).

4. Nunn, J. F. \& Matrhews, R. L. Gaseous Exchange during Halothane Anaesthesia: the Steady Respiratory State. Brit. J. Anaesth. 33: 330 (1959).

5. Egcers, C. W. N. JR.; dE Groot, W. J.; \& Tanner, C. R. Hemodynamic Changes Associated with Various Surgical Positions. J.A.M.A. 185: 1 (1963).

6. Aubry, U.; Denis, R.; KeÉri-Szántó, M.; \& Parent, M. Factors Affecting Survival of the Geriatric Patient after Major Surgery. Canad. Anaesth. Soc. J. 12: 510 (1965).

7. McDowall, D. G.; Harper, A. M.; \& Jacobson, I. Cerebral Blood Flow during Trichlorethylene Anesthesia: A Comparison with Halothane. Brit. J. Anaesth. 36: 11 (1964).

8. Alexander, S. C. et al. Cerebral Blood Flow and Metabolism during Halothane Anesthesia in Man. Fed. Proc. 22: 186 (1963).

9. Incvar, D. H. The Pathophysiology of Cerebral Anoxia. Acta Anaesth. Scandinav. Supp. 29: 47 (1968).

10. Epstein, R. M. et al. Studies of the Splanchnic Circulation during Halothane Anesthesia in Man. Anesthesiology. 26: 246 (1965).

11. McDowali, D. G.; Barker, J.; \& Bennetr, W. B. Cerebrospinal Fluid Pressure Measurements during Anaesthesia. Anaesthesia 21: 189 (1966).

12. Dawson, B. et al. Halothane and Ether Anesthesia in Gallbladder and Bile Duct Surgery: A Retrospective Study into Mortality and Hepatobiliary Complications. Anesth. \& Analg. 42: 759 (1963).

13. AUDET, J. et al. Halogenated Anesthetics and Innovar: A Comparative Liver Function Study. Proc. 111. Internat. Anaesth. Congr. 2: 78 (1964). 